\title{
PROFILE OF ANIMAL BITES AND TREATMENT SEEKING BEHAVIOUR OF VICTIMS IN A RURAL COMMUNITY OF WEST BENGAL
}

\section{Community Medicine}

Dr. Baisakhi Maji Asst. Professor, Dept. of Community Medicine, ID \& BG Hospital, Kolkata-700 010.

\begin{tabular}{ll}
\hline Dr. Jadab Ch. & Assoc. Professor, Dept. of Community Medicine, R. G. Kar Medical College, Kolkata- \\
Sardar* & $700004 .{ }^{*}$ Corresponding Author \\
\hline $\begin{array}{ll}\text { Dr Pankaj Kumar } \\
\text { Mandal }\end{array}$ & $\begin{array}{l}\text { Professor, Dept. of Community Medicine, Calcutta, National Medical College.Kolkata- } \\
700014\end{array}$
\end{tabular}
Manda

\section{ABSTRACT}

Rabies is practically $100 \%$ fatal \& it is a neglected tropical disease of world wide importance with about 60,000 deaths annually. Most of the cases occur in Asia \& Africa. Community based observational cross-sectional study was conducted in north 24 parganas, W. B. A house to house visit was done using pre-tested schedule and total 1516 persons were surveyed covering 288 houses among whom 32 animal bite cases were detected. Prevalence of animal bite $2.1 \%$, mostly males $(62.5 \%)$ and $71.95 \%$ were $15-60$ yrs, dog bite cases $(59.4 \%)$, common site of injury lower limb (68.7\%), all cat III victims were not given immunoglobulin \& $21.9 \%$ did not wash wounds \& $78.1 \%$ washed wound for $1 / 2$ minutes. Major cause lack of awareness and non availability of rabies immunoglobulin (RIG).

\section{KEYWORDS}

Post exposure prophylaxis (PEP) Rabies immunoglobulin (RIG) antirabies vaccine (ARV), stray animal.

\section{INTRODUCTION:}

Bite of warm blooded animals particularly carnivorous such as dogs, cats, jackals, wolves primarily cause zoonotic disease in man called rabies. ${ }^{(1)}$ It is practically $100 \%$ fatal \& poses a potential threat to over 3.3 billion people world wide. ${ }^{(2)}$ It is an epizootic \& enzootic disease of worldwide importance with about $60,000 /$ - deaths annually. Rabies is prevalent mainly in the developing countries of Asia \& Africa. ${ }^{(4)}$ Annual incidence of animal bits in India was $17 / 1000$ \& it was more in rural areas $(18 / 1000) \& 20000$ deaths are estimated to occur annually. ${ }^{(5)}$ Annual incidence of rabies was found to be $2 / 100000$ population.

Majority of bite \& victims belonged to poor socioeconomic status \& habitat of rural areas. In rabies endemic country like India where every animal bite is potentially suspected as a rabid animal bite. The treatment should be started immediately ${ }^{7,8}$ Rabies being a zoonotic disease, it cannot be eradicated but elimination or control is possible with timely and complete administration of post exposure prophylaxis (PEP), vaccination of pet animals \& awareness generation among community people to attain the goal of Rabies free India.

Limited no of studies were done relating to health care seeking behaviour of animal bite victims specially in rural areas of West Bengal. On this background, a rural community based study on profile of animal bites \& health care seeking behaviour of animal bite victims was done with the following objectives :-

To assess the socio demographic characteristics of animal bite victims, profile of wounds and treatment seeking behaviour of the victims.

\section{MATERIALS \& METHODS :}

The study was a community based observational descriptive study with cross sectional design. It was conducted at Amdanga community development block in North 24 Pargans district of West Bengal coming under field practice area of R. G. Kar Medical College, Kolkata .A total of 1516 population from six villages of Amdanga block was surveyed covering 288 houses, among whom 32 animal bite cases were reported. Six village were chosen by multistage simple random sampling technique. Families were selected from each village by simple random sampling technique on the basis on probability proportional to size (PPS).

Sample size of (1570) including 54 non responders was estimated by the formula $n=Z_{1}-\alpha / 2^{2}$ where $n=$ sample size, $Z=1.96$ ) at $95 \%$ c.i) $\& \mathrm{e}^{2} \mathrm{e}=$ relative precision (0.7) design effect 2 was considered for precision. From pilot study average family was 5.45 . So, 288 families were covered by house to house visit \& all the households were interviewed after taking their consent using a pretested semi structured proforma to collect information regarding $\mathrm{H} / \mathrm{O}$ animal exposure in last one year. Animal bite includes scratch, abrasion, licking etc. along with bite. All the data were analysed with the help of SPSS (statistical package for the social sciences) version 20. The results were expressed in proportions, frequencies, mean, standard deviation.

\section{RESULTS:}

Total 1516 population was surveyed covering 288 houses among whom 32 animal bite cases were reported giving the prevalence rate of $2.1 \%$ in the study area

Table -1 Socio demographic profile of animal bite victims $(n=32)$

\begin{tabular}{|c|c|c|c|}
\hline Socio demographic & Profile & No. & Precentage \\
\hline Age (yrs.) & $<15$ yrs. & 5 & 15.6 \\
& $15-60$ yrs. & 23 & 71.9 \\
& $>60$ yrs. & 4 & 12.5 \\
\hline Gender & Male & 20 & 62.5 \\
& Female & 12 & 37.5 \\
\hline Literacy status & Illiterate & 5 & 15.6 \\
& Literate & 27 & 84.4 \\
\hline Socio economic status as per Modified & Class II, III & 9 & 28.1 \\
B. G. Prasad's classification. & Class IV, V & 23 & 71.9 \\
\hline
\end{tabular}

The study showed majority $(71.9 \%)$ were in the age group of $15-60 \mathrm{yrs}$. $\&$ males were $(62.5 \%)$. Most of the victims $(84.4 \%)$ were literate \& $71.9 \%$ belonged to class IV \& V socio economic status as per modified B. G. Prasad's classification.

Table -2 Profile of bites $(n=32)$

\begin{tabular}{|c|c|c|c|}
\hline Profile of bites & \multicolumn{2}{|c|}{ No. } & Precentage \\
\hline Biting animal & Dog & 19 & 59.4 \\
& Cat & 11 & 34.4 \\
& Rat/mole & 2 & 6.2 \\
\hline Circumstance of & Provoked & 13 & 40.6 \\
bite & Unprovoked & 19 & 59.4 \\
\hline Time of bite & Morning & 11 & 34.4 \\
& After noon/evening & 19 & 59.4 \\
& Night & 2 & 6.2 \\
\hline Site of bite & Lower limb & 22 & 68.7 \\
& Upper limb & 7 & 21.9 \\
& Head, neck, trunk & 3 & 9.4 \\
\hline No. of wounds & $<3$ & 30 & 94.8 \\
& $\geq 3$ & 2 & 6.2 \\
\hline * Category of & Category II & 19 & 59.4 \\
wound & Category III & 13 & 40.6 \\
\hline
\end{tabular}

* Category I wound was not found. 
This study showed that $\operatorname{dog}(59.4 \%)$ was the main biting animal followed by cat (34.4\%). Most bites (59.4\%) in afternoon / evening. Common site of injury lower limb $(68.7 \%)$. Majority of wound $(59.4 \%)$ was cat -II type followed by cat III $(40.6 \%)$ as per W. H. O. classification of wound. No. of wound was less than three in $94.8 \%$ cases.

Figure: 1 Radar diagram showing distribution of bite victims according to the month of bite $(n=32)$

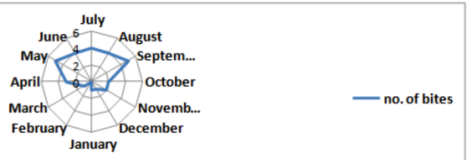

Radar diagram showed that victims were bitten mostly in May to Sept probably due to breeding months of biting animals.

Table -3 Treatment seeking behaviour of bite victims $(n=32)$

\begin{tabular}{|c|c|c|c|}
\hline $\begin{array}{c}\text { Treatment seeking } \\
\text { behaviour }\end{array}$ & & No. & Percentage \\
\hline Local wound washing & Yes & $* 25$ & 78.1 \\
& No. & 7 & 21.9 \\
\hline Time interval between bite & Within one hr & 13 & 40.6 \\
\& care seeking & Within 24 hrs. & 19 & 59.4 \\
\hline Type of treatment sought for & By T/T (yes) & 27 & 84.4 \\
& RIG & -- & -- \\
& ARV & 31 & 96.9 \\
& Indigenous & $* * 1$ & 3.1 \\
\hline Time interval between care & Same Day & 14 & 45.2 \\
seeking \& initiation of ARV & 2nd/3rd day & 17 & 54.8 \\
\hline Completion of all & Yes & 28 & 90.3 \\
intradermal doses & No. & 3 & 9.7 \\
\hline
\end{tabular}

*Washed wound with water/soap \& water for $1 / 2$ minutes only.

**Maduli / Jalpara was given only from traditional healer as the victim was seriously ill \& bed-ridden.

Among the victims majority $(78.1 \%)$ washed wounds with water or soap \& water but they washed wounds only for few minutes $(1 / 2 \mathrm{~min})$ instead of $10-15$ minutes. $6.3 \%$ applied mercurochrome on the wound.Only $40.6 \%$ attended health facility within one hr. of exposure. Almost all victims were administered with ARV vaccine (1.d) from govt. health facility. But none of the victims were given RIG due to its non availability. Only $45.2 \%$ were given ARV on same day of exposure as ARV clinic runs twice in a wk. 9\% did not complete full course of ARV due to their negligence, loss of wages etc. Most of them were given inj. T/T. One victim sought indigenous treatment like maduli, jalpara from traditional healers.

\section{DISCUSSION :}

The present cross-sectional study was done in a community of Amdanga block of North 24 Parganas.

This study showed that the prevalence of animal exposures was $2.1 \%$ where as the incidence of animal exposure was $18 / 1000$ as found by a multicentric study conducted by APCRI. ${ }^{3}$ But a study done in Kolkata by ghosh A \& Pal R showed very high prevalence $(8 \%)$ of animal exposure.

Majority of bite victims $(71.9 \%)$ were in the age gr of $15-60$ yrs. followed by children $<15$ yrs. $(15.6 \%)$. Majority of victims were $(62.5 \%)$ male \& literates $(84.4 \%) \&$ belonged to lower socio economic $(71.9 \%)$ status. Similarly, a study done by Karthik C, Viswanantha et al showed that most of the cases $(64.4 \%)$ were adults followed by children $(<15$ yrs.) \& majority of victims $(72.4 \%)$ were male. Another study done by Sudarshan MK, Madhusudana SN et all showed that rabies affect mainly the people of lower socio economic status due to their vulnerability. In this study $\operatorname{dog}(59.4 \%)$ was the biting animal is most cases followed by cat $(34.4 \%) \&$ most of bites were unprovoked (59.4\%) \& the time of bite was mostly in afternoon or evening $(59.4 \%) \&$ common site of injury was lower limb (68.7\%). Santra S, Lahiri SK et al showed that $49 \%$ were bitten by dog \& $45.1 \%$ by cat $\&$ lower limb $(58.8 \%)$ was the most common site of injury as $\operatorname{dog} \&$ cat are the most common pet animals. were from dog among whom $67.3 \%$ were stray dogs $\&$ most of bites were unprovoked. ${ }^{(15)}$

This study showed that seven victims $(21.7 \%)$ did not wash wounds at all \& 25 victims $(78.1 \%)$ washed their wounds only for one/two minutes. This was probably due to their ignorance, illiteracy, poor knowledge about rabies etc. A study from Surat showed that $67 \%$ washed the wound with water or with soap \& water. ${ }^{(16)}$

Present study showed that almost all (96.95\%) were injected with ARV from govt. facility but none who belonged to cat III bite $(40.6 \%)$ were given inj RIG as the immunoglobulin was not available at Amdanga block health centre. ARV was given on 2nd or 3rd day after bite as the ARV clinic runs twice in a wk. Another study from rural area of Tamil Nadu showed that $40 \%$ of victims washed wound with soap \& water \& majority $(76.4 \%)$ went to Govt. Hospital ${ }^{(17)}$

All exposed persons who went to govt. health facility were administered with ARV, but $9.7 \%$ did not complete the full course probably due to their negligence, busy with other work etc.

Similarly a study done in Govt. hospital showed that majority of bites (70.8\%) belonged to Cat III exposure \& compliance rate of full course was $77 \%$. ${ }^{(18)}$ It is important to complete the full course of vaccination to get complete protection

\section{CONCLUSION :}

Good community involvement, properly trained health care provider and uninterrupted availability of safe \& effective ARV including rabies immunoglobulin (RIG) are required to fight against rabies.

\section{REFERENCES}

1. Park K. Park's Text book of Preventive and Social Medicine, 24th Edition, M/s Banersidas Bhanot Publishers, Jabalpur (M.P.), India 2017, 294-96.

Bhalwar R. Bhalwar's Text book of community Medicine, 3rd Edition, Wolters Kluwer Pvt. Ltd. Publisher, New Delhi, India, 2019,736-38.

3. Assessing burden of rabies in India, APCRI : WHO sponsored National Multicentric Rabies Survey, 2003, available at http://www.rabies.origin/rabies/whosurvey.

4. Santra S. Lahiri Sk, Guha Ray, T, 'Determinants of Animal bite and practices following bite among the victims attending a block primary health centre of West Bengal', International Journal of Health Sciences \& Reseasch 2005, vol. 5; Issue 8, 24-7.

5. Sudarshan MK, Mahendra B J et al - An epidemiological study of animal bites in India, J. Communicable diseases 2006 March, 38 (1):32-39.

6. Sudarshan MK, Madhusudana S N et al - "Assessing the burden of human rabies in India : Results of a National multicentric epidemidogical Survey", Int J. Infections diseases 2007, Jan II (1): 2135 .

7. National guidelines for management of Animal bites, available at http:/ www rabies origin/rabies/journal/rabies07/guidelines.htm.

8. Guidelines for animal bite management, National rabies control programme, Guidelines for animal bite management, National rabies control
Directorate of Health Services, PH \& CD branch, Govt. of W. B., Oct. 2019

Directorate of Health Services, PH \& CD branch, Govt. of W. B., Oct. 2019.
Bhuyan P. J. - Epidemiology, prevention \& control of rabies in India - A review study, Journal of Evolution of Medical and Dental Sciences 2012; 1(3): 180-4 available a http//www.jemds.com/date pdf/bhuyan/rabies.pdf.

10. Ichhpujani RL, Chhabra $\mathrm{M}$ et al - knowledge attitude \& practices about animal bites an rabies in general community - Amulticentric study. J. Comm diseases 2006; 38: 355-61.

11. N. Agarwal, V. P. Reddaiah, 'knowledge attitude and practice following dog bite : community based epidemidogical study; Health and Population. Perspectives and issues 26(4) 154-161,2003, available at http://www.ncbi.nlm.nihgov/pubmed.

12. Lawnga SK, Lemeshow S, Sample size determination in Health studies - A practical manual, World Health Organization, Geneva 1991:p-1,17,72.

13. Karthik C, Viswanantha PG et al - profile of dog bite cases attending the outpatien department of an urban health training centre in Bangalore City, India, Int Journal Community Medicine Public Health 2016; 3:1765-68.

14. Ghosh Ayan, Pal Ranbir, Profile of dog bite cases in an urban area of Kolkata, India, National Journal of Community Medicine, vol.5, issue 3, Apr.-Jun 2014, 321-4, available at http//www.njcmindia.org.

15. Hardanahalli RS, Annadani R, Undi M et al. Economic costs of rabies post-exposure prophylaxis, India J. Community Health.2017, 29(2):156-61.

16. Umarigar P, Parmar G, Patel PB et al. Profile of animal bite cases attending urban health centre in Surat City, A cross sectional study. National J of Community Medicine 2012, 3 (4): 631-5.

17. Sangeetha $\mathrm{S}$, Sujatha $\mathrm{K}$ et al; An epidemiological study of animal bites among rura population in Tamil Nadu, India, Int J. Comm Med. Public Health 2016; 3 : 1413-8.

18. Shankaraiah RH, Rajashekar RA, Veenav et al. compliance to anti-rabies vaccine in post-exposure prophylaxis. Indian J. public Health $2015,59 \cdot 58-80$. 